\title{
Exploring Language; Some Specificities, Complexities and Limitations in Human Communication and Social Interaction in Multi-cultural Contexts
}

\author{
Kelechi Chijioke Samuel
}

School of Media Communication, Pan-Atlantic University, Ibeju-Lekki, Lagos, Nigeria

*Corresponding author email: kelechi_nwagbara@yahoo.com

Received: 02 July 2018 / Revised: 05 November 2018 / Accepted: 21 January 2019 / Published: 02 February 2019

\begin{abstract}
This paper explores the subject matter of human language as a social phenomenon in a multi-cultural and multi-ethnic society like Nigeria. The paper situates language as a complex social phenomenon which pervades every aspect of human life. It identifies the role of language in intrapersonal and interpersonal communication, and the complexities involved in every communicative event that must not be taken for granted. Furthermore, it identifies the functions and limitations of language, including its negative functions as viewed from Critical theory. The paper affirms that language is a central phenomenon in human cognitive development, internal conceptualization of thoughts and ideas, the external expression and sharing of thoughts, the perception and representation of social reality, the transmission of culture, and the maintenance of social relations. The paper further notes that language difference can be a source of social dysfunction in multi-lingual and multi-cultural societies like Nigeria.
\end{abstract}

Keywords: Language, human communication, thought, cognition, perception, culture, social dysfunction.

\section{Introduction}

Language is the vehicle of communication and human socialization. There can be no communication without some form of language. Human language is a unique and symbolic communication system that is developed and learned through socialization, rather than being biologically inherited. But some scholars have argued that human language is a natural extension of biological capabilities. That is, language is a prelinguistic form of consciousness and communication which evolved over time, in the traditions of Darwinian evolution. Pinker and Bloom (1990), published one of the prime articles in this regard. They argued that there is every reason to believe the human "language instinct" originated through a process of classical Darwinian evolution. Scholars like Chomsky reject the evolutionary view. Chomsky (2006) argues that human language is a unique ability enjoyed only by humans, insisting that language is a social phenomenon, developed and learned by humans for the purposes of social interaction. Extant literature recognizes human language as a social phenomenon that is largely an abstract and arbitrary creation used to conceptualize and represent perceived reality and cognitive processes. As the debate about human language continues it is important to note that regardless of which side of the debate one argues from, what is incontrovertible is that: (i) language can be invented, (ii) the signs and symbols that constitute language are arbitrarily assigned, and, (iii) language evolves over time.

Language holds the key to human social interactions starting from the intrapersonal processes of cognition and perception to the interpersonal processes of relating with others. But despite the role language plays in human social interaction, it is fraught with challenges and limitations. These problems and limitations manifest especially in multi-lingual and multicultural societies where language has to cross social boundaries. Some of the problems associated with multi-cultural and multi-lingual societies include rivalry, hegemony, inequality, tribalism, ethnocentrism, bigotry and other manifestations of prejudice that promote social 
Exploring Language; Some Specificities, Complexities and Limitations in Human Communication and Social Interaction in Multi-cultural Contexts

exclusion. Nigeria, as a multi-ethnic society with over 300 different ethnic nations and distinct ethnic languages, is enmeshed with some of these problems. This relatively large number of ethnic languages poses a challenge to national communication and social cohesion. For historical reasons, English is the official language of communication in Nigeria. The implication of this is that each individual, while speaking English, brings an unintended linguistic baggage to official communication. This is reflected in barriers to communication such as accents which sometimes obscure meaning in spoken communication. For reasons not too far-fetched, these language differences pose challenges to national cohesion. This paper among other things, sets out to explore the subject matter of language with a view to identifying its use, misuse, limitations, complexities and specificities, and how all these potentially impact human communication and social interactions in multi-cultural and multi-lingual societies.

\section{Language and Communication}

To explore the subject further, it will be pertinent to define the term, language. Kendall (2015, p. 63) defines language as 'a set of symbols that expresses ideas and enables people to think and communicate with one another.' For Kendall, language consists of symbols and plays a critical role in human cognitive and communicative processes. Sapir (1921) argues that language is a purely human and non-instinctive method of communicating ideas, emotions and desires by means of voluntarily produced symbols. In their own contribution, Bloch and Trager (1942) state that language is a system of arbitrary vocal symbols by means of which a social group co-operates. Furthermore, Weiten (2007), states that a language consists of symbols that convey meaning, plus rules for combining those symbols, that can be used to generate an infinite variety of messages. According to Goldstein (2008), language is a system of communication using sounds or symbols that enables us to express our feelings, thoughts, ideas, and experiences. Thus, we can distil that language is an organised system of rules and structure of communication that consists of signs and symbols that are used in conveying meaning and shared by a social group. But all of these rules operate within contexts of human culture and society. Human communication research assigns communication a central role in the human experience. Understandably so because, the human experience is essentially anchored on the social nature of human society. This nature is interactional, relational and communal. Communication underscores the interdependence of humans, and the need to forge bonds of co-operation for mutual benefits. Literature affirms that communication involves the following elements: source/sender, message, channel, receiver, encoding, decoding, feedback, noise and context. All these elements play their roles in a communicative event because of the availability of a common language that is understood by parties in the event. In the process of communication, people use language symbols to encode and decode messages based on the meanings assigned to the symbols, objects and things in the context. So, messages and their interpretation are the key subject of communication study.

In human communication, language plays a functional role in thinking, conceptualising and communicating perceived reality. Language is required for reasoning and making inferences. It helps provide a reference point for human cognition. It is a necessary vehicle for human thought. Hobbes (1655) and Locke (1690) as cited by Lotter (2016) assigned two main characteristic uses to language with regard to thought. Firstly, language is used for memorization, and/or in the representation and recording of one's own thoughts. Secondly, it is a required vehicle for communicating one's own thoughts to other people. So, language is required for both intrapersonal and interpersonal communication, and indeed, other levels of communication. However, it is only partially correct to argue that language is used for memorization. What is omitted in the above assertion about language and thought is that human cognitive processes and memorization also include the memorization of images which do not need language to achieve. For instance, an individual can successfully memorise and store an image such as the face of someone, an object, an animal, or even an abstract experience without needing to use language in the process. But some form of language may be needed to communicate such images to another individual.

Perhaps language is most relevant in interpersonal communication than for intrapersonal communication. Intrapersonal communication involves thinking, planning, and internal conflict resolution as individuals 
Kelechi Chijioke Samuel, Adv. J Social Sci.; Vol. 5 Issue 1, pp: 26-36, 2019

evaluate alternative choices and courses of action. It involves some form of internal sense making and contemplation that may not be vocalised. Intrapersonal communication occurs in the mind and involves the individual's perception, memories, experiences, feelings and emotions, values, culture, gender, among other factors. As noted earlier, this does not necessarily require language because child psychology has revealed that small children also engage in cognitive processes even when they have not learned any language. Nevertheless, as children grow older and learn languages, they begin to apply language as a frame of reference in their mental activities and a cognitive tool kit for conceptualizing and storing thoughts and ideas. Language also plays a central role in person to person (interpersonal) communication in the following ways: a) language is used in the conceptualisation of the message by the sender, b) after conceptualisation, the message is encoded using language; c) upon receipt of the message, by the receiver, it is decoded and interpreted using language, and while giving feedback, language is again used to achieve this; d) language ambiguity can constitute noise in the process of communication. The following guides to interpersonal communication encapsulate the use and importance of language in the process of communication.

\subsection{Encoding and Decoding of Messages}

This means that language is used as the basic element for encoding and decoding meaning. Therefore, careful attention should be given to the choice of words, signs, symbols and other forms of language. This is because the same composition of words can have different meaning in different contexts or when interpreted alongside other accompanying forms of verbal and non-verbal cues. For this and other reasons, the same composition of words can have different meaning to different parties in the same context. This is because interpretation is autonomous to the receiver and independent of the sender. Thus, giving consideration to semantics, pragmatics and other factors while encoding messages is important. If one is not careful about choice of words, the accompanying verbal/non-verbal cues (body language), and the context in which they are used, there may be an increased risk of being misunderstood. The speech act theory discussed below clarifies this idea in some way. Also, there are ethical and socio-cultural considerations in the use of language. Giving due consideration to ethics in language use while encoding meaning into messages is important. In this regard, the cardinal virtues of prudence, justice, fortitude and temperance come to mind. Language use must be prudent and just in every circumstance. Language use must also reflect the character of courage and temperance in the message encoder and sender. When encoding and decoding messages the use and interpretation of language must also reflect socio-cultural contexts and environments because these factors impact language use and interpretation. This is especially important in a world that is increasingly becoming global yet local - glocal.

\subsection{Communicative Intention}

Communicative intention is anchored on the fact that there are literal and non-literal meaning of words in most languages. This underscores the fact that language is always used with an intention to communicate certain meaning(s) in the message. In other words, individuals use language with a communicative intent. The communicative intentions in certain messages may exist in the non-literal meaning of the words used or in the body language accompanying the words spoken. Non-literal meaning of language may be intended or unintended. The use of language requires caution so that unintended meanings are avoided as much as possible. Understanding communicative intention in the use of language requires participants to go beyond the literal meaning of the words in order to successfully extract the speaker's intended meaning. However, the danger in this is that the sender's meaning may be missed if the wrong socio-cultural context is applied or if the non-literal meanings are misconstrued. Understanding semantic, pragmatic, figurative and connotative use of language is vital in this regard. Communicative intention can also be seen in the speech act theory presented by Austin (1962); Searle (1969). Under the theory, any utterance can be thought of as constituting three rather different types of acts: a) locutionary act - the act of uttering a specific sentence with a specific conventional meaning. In this instance, the speech is a direct demand emanating from the literal meaning of the words used; b) an illocutionary act - the act of demanding, asserting, promising, etc. 
Exploring Language; Some Specificities, Complexities and Limitations in Human Communication and Social Interaction in Multi-cultural Contexts

through the use of a specific locution. Here, the illocutionary force of a speech corresponds to its intended meaning, even if it is not a direct demand, it makes a proposition to the recipient; and, c) perlocutionary act - an attempt to use words to make a particular effect on the addressee. In this instance, the speech act is viewed from the direct and indirect psychological effects the words may have on its recipient.

\subsection{Perspective Differences}

This guide highlights the fact that individuals in a communicative event have different perspectives and world views. So, same words or composition of words in the same context may be interpreted differently by different individuals. Recognising perspective differences requires that one gives consideration to the perspective of the message recipient(s). This means, the form and substance of a message is influenced as much by the message recipient as it is by the message sender (Krauss, 1987). In a sense, this consideration is at the core of the uses and gratification theory, where media content is fashioned to the pleasure and gratification of the audience. This thinking is echoed by Brown (1965) who noted that effective message coding requires that the point of view of the recipient be realistically imagined. Perspective consideration may be spatial or conceptual. Spatial perspective refers to taking (location, position, etc.) into account in message formulation. Conceptual perspective means that the psychographic profile (cognitive inventory, values, beliefs, motives, etc.) of the message recipient is taken into account in message formulation (Schober, 1993). Spatial and conceptual profiles may be inferred from geographic location, social category membership and situational context of individuals.

\subsection{Dialogic Approach to Communication}

The dialogic approach to communication means that parties to a communicative event approach communication as a dialogue and a collaborative process. This means the negotiation of meaning in communication is achieved through the co-operation and collaboration of the communicating parties. This is different from the other three approaches where meaning was either derived from the message content, instigated by the sender's intentions or created with the receiver's perspective in mind. However, all of these approaches are weaved into dialogic communication. In dialogic communication feedback is not just a response from message recipients to the initial message but an important and necessary activity in the process of generating meaning during communication. As a collaborative process, Clark \& Brennan (1991) as cited in Krauss \& Chiu, 1998, p. 12) observe that just like it takes two consenting and co-operating individuals to play a duet, shake hands, ...or make love, to succeed in language communication, the sender and the receiver have to co-ordinate the content and process of communication. Jürgen Habermas' writings on discourse underscore this approach to communication.

\section{Functions/uses of Language}

The functions of language in human social interaction can be seen from two broad approaches - the functional and the critical approaches. The functional approach looks at what language is used for in everyday life. Whereas the critical approach looks beyond the surface to unearth hidden uses of language. Essentially, the Critical approach typically examines social phenomenon in order to uncover hidden structures that predispose such phenomenon to promoting the oppression of social groups. The critical approach become even more important in multicultural societies as issues of hegemony are considered in the context of socio-political relations between people of different cultures and languages living in one social context. On a functional level, language provides the framework for organizing thought and the conceptualization of ideas. Language facilitates the internal discourse or monologues that take place during intrapersonal communication activities such as thinking, meditation, reflection, analysis and reasoning, perception and memorization. Language creates a system for organizing human thoughts and ideas. As thoughts occur in the human mind, language provides the signs and symbols for signification and organisation. Cognitive psychology suggests that children think differently from adults partly because a significant part of their language repertoire has not fully developed. Language is a vehicle that facilitates 
Kelechi Chijioke Samuel, Adv. J Social Sci.; Vol. 5 Issue 1, pp: 26-36, 2019

cognition. This is closely related to the conceptualization of thought and ideas. Language enables humans perceive and interpret stimuli in the process of learning about the world. Put differently, language provides the symbols and resources for representing what and how people perceive and interpret the world - social cognition and construction. Language provides scaffolding for the construction of concepts.

Language is the means for communicating, expressing and sharing thoughts. Reddy (1979 p. 290) argues that language functions like a 'conduit used to transfer thoughts and ideas from one person to another; in writing and speaking, people insert their thoughts and feelings in the words; words accomplish the transfer by containing the thoughts or feelings and conveying them to others; and in listening or reading, people extract the thoughts and feelings once again from the words.' Reddy underscores the conduit/transport metaphor of language use, and suggests that within the concept of transporting meaning, language functions in several ways. From the standpoint of its expressive functions, language is used to express the views, beliefs, ideas, thoughts, feelings, attitudes and needs of the sender in a communicative event. Language is the vehicle for encoding and decoding meaning in the process of communicating and sharing thoughts. Language enables humans share experiences, perceptions, feelings and knowledge. From the perspective of receivers, language is used to evoke a response/reaction. Humans, through language, possess the unique ability to manipulate symbols to stimulate desired response from others. Words are used to send a message that is intended to evoke a response. In other words, the message is sent using words that are intended to make the receiver perceive the message in a particular way and to evoke a response. Furthermore, from the standpoint of constituting a subject matter of communication, language has referential function in that, it is used to describe, analyse and explain reality. In summary, language provides a systematic mechanism for perceiving, representing, memorizing, manipulating and expressing reality.

Language is the principal means by which culture is transmitted within society. Language and culture are intertwined in the sense that language is transmitted culturally, while culture is transmitted through language. In other words, language is learned in the context of cultures and language is used to maintain and convey culture and cultural ties over time. Language allows human experience to be storable, retrievable and shareable. Cultural knowledge, norms, beliefs and values are embedded in language. Language enables cultures pass on the body of knowledge, beliefs, values, norms and other aspects of non-material culture from generation to generation. Language performs social function. In this sense, language serves to establish and maintain social contact between individuals in a society or group. And because man is a social and gregarious being, language facilitates the dialogic, discursive and relational needs of humans which may include the need to express and share emotions. It also provides a system with infinite possibilities for the creative expression of feelings and emotions. This is sometimes referred to as the phatic function of language.

In the traditions of Critical theory, language is seen as a source of power and social control, and that it provides a mechanism for perpetuating racial and ethnic inequalities between people and groups (Tannen, 1993). Critical theorists argue that language promotes ethnic and cultural hegemony. Dominant cultures use language to perpetuate political and cultural domination. Imperialists use language to establish and maintain political and cultural hegemony. This is evident in colonial relationships in Africa and across the world where colonial powers typically impose their language on their colonies while relegating local languages to obscurity.

Language is also viewed as a tool for establishing and maintaining unwholesome and oppressive mind-sets such as stereotypes, gender characterisation and chauvinism. The use of metaphors and other terms to characterise, objectify, oppress and denigrate women and other minority groups, falls into this category. Feminist writings like Spender (1980), Lakoff (1973) and others argue that men dominate and control both interactions with women and the language system itself. And for that reason, women use language in a way which reflects their subordinate position in society, while men use language in a way that reflects their power. The observed differences in men and women's speech is due to men's dominance and women's subordination. And so, language is more about power and status than gender. Language as an aspect of religion is used to perpetuate intolerance, bigotry and exclusion. Religion uses language to promote perceptual bias, 
Exploring Language; Some Specificities, Complexities and Limitations in Human Communication and Social Interaction in Multi-cultural Contexts

dogmatism and extremism. Religious fundamentalism is due largely to the misuse of language to promote exclusion and hate. Also, religious leaders are known to use language and the interpretation of religious texts as tool for manipulation and control of the faithful. Religious language and chants are also used as tools to mystify and control members of a religious system or group.

\section{$4 \quad$ Language and Thought}

Many times, language is perceived in terms of its verbal characteristic (speech), but language philosophers have argued that while phonology, remains a key component of language, it is not essential that language must be spoken. Language can be verbal (spoken) or non-verbal (written or gestured- sign language). But it is important that language must first, be thinkable, whether spoken or not. This is because humans do not think in words, but in the images words conjure in the mind, and therefore such images must be representable in words or gestures. Since the vocabulary and components of human languages vary considerably in the information they convey, scholars have long wondered whether different languages might impart different cognitive abilities on language users. Philosophers have debated the relationship between thought and concepts (cognitive processes) and language. The likes of Immanuel Kant, Johann Georg Hamann and Johann Gottfried von Herder of the German intellectual community made significant contributions in the study of language philosophy. The critical issues that engaged the likes of Kant, Hamann and Herder and other scholars were the issues of thought and language. It appears that the popular school of thought, especially during the Enlightenment era, was that there is duality of thought and language. In other words, language and thought (concepts and ideas) were separable from whatever language in which they were expressed and therefore can occur independently and autonomously. And that language is merely used as a convenient and necessary means of memorising and communicating ideas.

Against this popular opinion of that era, Hamann and Herder in their writings (Metacritique on the Purism of Reason $(1784,1800)$ and Metacritique on the Critique of Pure Reason (1799) respectively), as cited by Forster (2012, p. 485), introduced a new and contrary paradigm which argued the unity of thought and language. This paradigm argues that "thought is essentially dependent on and bounded by language". Hamann actually argued that thought was practically synonymous with language and that concepts and meanings are not independent of language but are merely usages of words. In summary it may be correct to argue that Kant, Hamann and Herder all acknowledged some sort of causal dependence of human thought and language. While Hamann and Herder were apostles of linguistic determinism, it appears that the writings of Kant at different time periods (Critique of Pure Reason (1781), Critique of Practical Reason (1788) and Critique of Judgment (1790), argued for linguistic determinism and also for duality of language and thought (that thoughts were sovereign and independent of language).

Even in modern times, the idea that language affects cognitive abilities remains controversial, especially, since American linguists, Edward Sapir and Benjamin Lee Whorf, put forward their hypothesis that speakers of different tongues may think differently. According to the Sapir-Whorf hypothesis, language not only expresses our thinking and perceptions but also shapes them. The language system or "descriptive terms" that we know and can use influences our perception and conception of reality. Although their ideas seemed popular at the onset, a lack of empirical evidence to support the claim affected its wide acceptance. The key question is, if humans are only able to think through language, then language must precede thought. And if language precedes thought, then it follows that the vocabulary and grammar of a language will influence what is perceived/conceived and how it can be perceived/conceived in the human mind. This scenario describes the paradigm referred to as linguistic determinism. An alternative to this theoretical paradigm is linguistic relativism. On this point, I stand with those who argue that language and thought are independent, even though without doubt, language provides a useful reference for the conceptualization and communication of thought.

Boroditsky (2011, p. 63-65), however notes that, 'empirical evidence for this causal relation has emerged from several studies' (Boroditsky \& Gaby (2010); Danziger \& Ward (2010); and Ogunnaike et al (2010). There seems to be some indication that one's mother tongue does indeed mold the way one thinks about 
Kelechi Chijioke Samuel, Adv. J Social Sci.; Vol. 5 Issue 1, pp: 26-36, 2019

many aspects of the world, including space and time. Their findings suggest that language and thought are interdependent in more ways than scientists had previously realized. The evidence overturns the longstanding dogma about universality of thought and human attitudes. It provides interesting insights into epistemology and the construction of reality, and also presents interesting hypotheses that researchers can pursue. While the debate on thought and language remains, again, I would argue that thought and language are distinct concepts that exist separately. Given that language is essentially made up of arbitrary creations used to describe and explain perceived reality, it is conceivable to think without language. Like Kant noted, people only "fabricate signs in order to express that which they think", and with time it becomes part of human language. However, language systematizes and gives a definite shape to thought and this enables memorization and retrieval of thought. As the debate about language and thought continues, what is incontrovertible is the fact that language and thought are often inseparable.

\section{$5 \quad$ Language and Psychology}

It is evident that language pervades social life and constitutes the primary means by which we gain access to the contents of other people's minds. Language is the typical medium through which they seek and gain insight into the minds of respondents in social psychology research. Language is implicated in personality development and self-image, social perception, intergroup bias and stereotyping, social interaction and other phenomena that have engaged social psychologists. Personality influences the use of language for both intrapersonal and interpersonal communication. The human personality encompasses the self-image, beliefs, values, ethical standards, attitudes and preferences, etc., that an individual subscribes to. These factors influence perception, emotions and choices. They influence the interpretation of messages, the negotiation of meaning, and the social construction of reality and knowledge. For example, personality influences virtue ethics and the choice of what is considered morally right or wrong by the individual.

It is therefore conceivable to argue that language impacts the human cognitive processes of perception, memory, thinking, conceptualization, philosophy and decision making, uncertainty reduction and memory. The philosopher Rene Descartes is quoted as stating that, "I am certain that I can have no knowledge of what is outside me except by means of the ideas I have within me." (Smith, 2016, p.1). This statement underscores the importance of thoughts and by extension language, as the vehicle for the conceptualization of thought. Human memory as part of the internal cognitive process involves the internal encoding of information for future recall and use. An individual encodes, stores and retrieves information from memory. The Schema theory on cognition is based on this thinking and tries to explain how people process information. Schema as a human cognition structure or system consists of the organised inventory of knowledge an individual has stored-up about situations, subjects, objects and the general environment which has been taken from their prior experiences. It is used for processing new information and retrieving stored information. It is argued that the storage and retrieval of information using schemata is achieved through language.

In psychology, the theories of personality and cognitive development by Sigmund Freud, Erik Erikson, George Herbert Mead and Jean Piaget, try to explain the internal cognitive processes that occur in individuals. Freudian psychology as reconceptualized by Jacques Lacan, using Saussure's linguistic structuralism (signifier, signified and signification), highlights the important role of language and speech in psychoanalysis and other aspects of learning and personality formation - the self, the psychic and sexual life. Mead (1964) in his theory of the self and thoughts on symbolic interactionism, argued that, the development of the self is intimately tied to the development of language and the symbols therein. The cognitive development theory of Piaget implicates language as one of the raw materials or building blocks used in the creation of schemata upon which subsequent assimilation and accommodation of the external world are built in the mind of the child. Piaget argued that part of the reason children think differently from adults was because a significant part of their language has not developed. Children typically use gestures and sounds to express their thoughts and since gestures and sounds unlike words are grossly limited, they cannot express everything in their thoughts. Children therefore remain partly prisoners of their own minds. 
Exploring Language; Some Specificities, Complexities and Limitations in Human Communication and Social Interaction in Multi-cultural Contexts

This situation is made clearer as we reflect on the relationship between our mastery of language vocabulary and our ability to understand the thoughts of others as well as express our own thoughts. This is the reason language is one of the primary aspects of human culture taught to children. Therefore, where there are gaps in the mastery of language there will be gaps in ability to communicate with and understand others in the society.

\section{$6 \quad$ Language and Culture}

There is consensus that language is an integral part of non-material culture, and that language is the principal means by which cultural knowledge is transmitted from person to person and from one generation to another. Exploring the relationship between language and culture is therefore important. Kendall (2015, p. 59) defines culture as "the knowledge, language, values, customs and material objects that are passed from person to person and from one generation to the next in a human group or society". Baran (2010) has argued that culture is the medium evolved by humans to survive, and through which all of life's events must flow. These definitions give culture a central role in human social relations. Geertz (1973, p.89) opines that culture is a historically transmitted pattern of meanings embodied in symbolic forms by means of which people communicate, perpetuate, and develop their knowledge about, and attitudes toward life. By suggesting that culture involves the transmission of patterns of meaning, Geertz implicates language in culture. Culture is the learned and socially acquired traditions and lifestyles of members of a society. It includes their preferred and repetitive ways of thinking, feeling and responding to their environment. Thus, culture is implicated in intrapersonal communication and the cognitive processes of people.

From the above perspectives on culture, one can argue that culture consists of the body of knowledge, symbols, values, customs, beliefs, material objects and language that are shared by people and transmitted from one generation to another. And that culture consists of two broad aspects - the material and the nonmaterial. Material culture typically consists of the physical artefacts or objects created and used by members of a particular culture. This can be termed hard culture or cultural hardware. Material culture will include physical creations such as foods, housing/shelter, dressing/clothing, art, ornaments and jewellery, weapons, furniture, tools, implements and technologies of work, etc. Non-material culture on the other hand consists of the abstract and intangible creations of the society that govern human conduct in the society. This can be termed soft culture or cultural software. This includes abstract creations such as language, symbols and gestures, knowledge systems, beliefs and values, norms and mores, religion and faith, customs and tradition, systems of governance, rules of conduct, etc., that influence and moderate the life of a people. Language is required to name and identify the material and non-material elements of culture. And so, it will be impossible to transmit culture without a base language for sharing meaning. Language enables culture to be storable, retrievable and shareable. It enables people within a society to share their experience and understanding of the past and to develop common perceptions and expectations of the future, and provides for complex, shared, goal-directed behaviour.

As earlier stated, language consists of a system of symbols that can be used in an infinite number of ways to generate meaning and communicate abstract ideas and thought. Each word in a language is a symbol to which a culture attaches a particular meaning. It is therefore the basic and primary vehicle for sharing meaning among people of a culture. Both material and non-material cultures are constituted using language. And this is essentially why the meanings that people associate with different objects, sounds and symbols can vary greatly from one culture and people group to another. Language is largely symbolic in every culture. This is because anything can serve as a symbol, insofar as it makes meaning to a specific community. From a semiology point of view, there are different symbolic forms in different cultures, and this reflects in language and its structure. Therefore, the connection between a symbol and its referent is not intrinsic to the symbol itself rather it is a function of agreed use, custom, or convention established within cultures. It is in this sense that language is symbolic. In summary one can argue that cultural knowledge, norms, beliefs and values are embedded in language. And that culture provides the context for the development of the signs and symbols that constitute language as a human communication system. 
Kelechi Chijioke Samuel, Adv. J Social Sci.; Vol. 5 Issue 1, pp: 26-36, 2019

The impact of language on culture and vice-versa means that communication events in multi-cultural societies like Nigeria becomes very complex and must be approached with circumspection. Clearly, the problem culture brings to communication is intensified in multi-cultural societies. It manifests in politics, economics, religion, education and other aspects of social interactions. Language and cultural differences, when not well managed often lead to tribalism, ethnocentrism and other forms of prejudice that promote bigotry and compromise social inclusion and peace. Rabushka and Shepsle (1972) noted in their studies on democracy and political instability in Ceylon (now Sri Lanka), Northern Ireland, Cyprus, Mauritius, Rwanda and Zanzibar, five nations with multi-ethnic/multicultural societies, that ethnic and cultural domination can breed militancy and social instability in plural societies. These countries have suffered major social and political instability, and in some instances, violent insurrections by those people groups who feel dominated. Their studies observed that there was a possible relationship between resistance to ethnic/cultural domination and political/social instability. In multi-lingual and multi-cultural societies there needs to be a balancing act by leaders of thought in all segments of society, if there is to be any chance of harmony and social inclusion.

\section{$7 \quad$ Limitations of Language}

As important as language is to human social interactions, there are significant limitations to social interactions that language impose. These limitations exacerbate the problems language bring to the process of human social interactions in a multi-lingual and multi-cultural society. Drawing from the functions and uses of language as well as its role in cognitive psychology and human culture, there are inherent limitations that language imposes on the communication process. Thus, as individuals from multi-cultural and multilingual societies interact, there are both intended and unintended consequences of language use in social relations. The argument that language determines thought (linguistic determinism) has implications for perception and the social construction of reality. It means that some aspects of reality that do not exist in vocabulary and grammar of a language may never be perceived and/or described. For example, it is reported that the Eskimo language has over 20 words associated with snow, which makes it possible for speakers to perceive and make subtle distinctions about snowfalls. But in most other languages, snow is snow. Therefore, such subtle distinctions may not be perceived let alone described. In this sense, different languages have limitations in the ability to express thoughts or describe perceived reality. Another instance is in the expression, I love you. When translated from the English language to the Igbo language of central south east Nigeria, it becomes, I saw you in my eyes or I saw you with my eyes. Now, this totally obscures the intended meaning, doesn't it? This problem of professing one's love for another becomes even more problematic if a Greek was speaking to a non-Greek. We learn from the Greek language that there may be more than six words for love in Greek - agape, eros, ludus, philia, philautia, pragma and storge. This presents a challenge for cross-cultural communication.

Language can introduce intended and unintended ambiguity in the communication process. And this can lead to the obscuring of meaning. Consider this statement for an example. What has the cat in its paws? What does this statement mean? It could mean, what does the cat have in its paws? But it could also mean what creature has the cat in its paws? In a nut shell, the possibility of introducing ambiguity constitutes a limitation in the encoding, decoding and interpretation of meaning intended in messages. Also, there are challenges of translation and transliteration in language use. For example, in the English language one would say, "you spent time" or "you wasted time". An attempt to express the same basic idea in the Igbo language of central south east Nigeria, and translate same back to English would be, "you killed time" or "you ate time". This means that ideas expressed in one language may have problems of translation and transliteration when an attempt is made to reproduce same in other languages. Of course, language scholars are familiar with this problem. In another instance that showcases the limitations of language, there are times when we have feelings or ideas inside our minds, yet we say, "I don't know how to describe it". It means language can limit the expression of thought or the description of what we perceive as humans. But then, it also means that thought can take place without language - duality of language and thought. In other words, language 
may influence thoughts and the interpretation of social reality but does not determine it (Linguistic relativism). Language is not universal and therefore limited in scope.

No one language can be understood by all humans, and no one language can express all thoughts, feelings and concepts. Even when meaning is properly constructed with language that is unambiguous and clear, there can still be misunderstanding of meaning by the receivers. Regardless of whether a communicating party judiciously follows all rules of grammar and sentence construction, meaning may still be misconstrued because there are many factors that influence the communication process. In this sense, language is still limited. Communicating parties must therefore keep this in mind and be prepared for post-communication event feedback.

\section{Conclusion}

It is established that language performs key functions in human social life. It significantly impacts the internal cognition, external perception and knowledge diffusion processes that shape the world-view of individuals. This definitely means that people with diverse linguistic and cultural backgrounds are likely to think and perceive the world differently. Also, as viewed by Critical theorists, language is seen and used as a source of power and social control. It provides a mechanism for perpetuating social inequalities, stereotypes and oppressive mind sets that promote social dysfunction. Many of these social issues manifest and dog contemporary Nigeria. In Nigeria, people from different cultures and language have to officially communicate in a foreign central language, English. For many people, especially, those who have learnt a local mother-tongue, there may be inherent distortions in the process of originating thoughts in one language and translating same to a foreign language using vocabulary that one may not be grounded in. This may lead to miscommunication. Communicating parties should keep such possibilities in mind. Thus, attention should be given to context and how messages are encoded so that they capture the communicative intent, reflect perspective differences and achieve some measure of consensus in dialogue. This is especially important in the digital age where media messages have the potential of traveling far in a very short time. This paper highlights the fact that the inherent challenges in the functions and uses of language have promoted social dysfunction and lack of cohesion in Nigeria due to the country's multi-lingual and multicultural nature. It is important to note, however, that language difference is not the only cause of social dysfunction and a lack of national cohesion in Nigeria. There are other contributing factors, but the paper seeks only to highlight the role language plays in this problem.

\section{How to Cite this Article:}

Samuel, K. (2019). Exploring Language; Some Specificities, Complexities and Limitations in Human Communication and Social Interaction in Multi-cultural Contexts. Advanced Journal of Social Science, 5(1), 26-36. Doi: 10.21467/ajss.5.1.26-36

\section{References}

Austin, J. L. (1962). How to do things with words. Oxford: Oxford University Press.

Baran, S. J. (2010). Introduction to mass communication. Media literacy and culture. New York, NY: McGraw-Hill.

Bloch, B., \& Trager, G. (1942). Outline of Linguistic Analysis. CA: Linguistic Society of America, Waverly Press

Boroditsky, L., \& Gaby, A (2010). Remembrances of times east: Absolute spatial representations of time in an Australian aboriginal community. Psychological Science, 21, 11, 1635-1639.

Boroditsky, L. (2011, November). How language shapes thought: The languages we speak affect our perceptions of the world. Scientific America, 63-65.

Brown, R. (1965). Social psychology. New York: The Free Press.

Chomsky, N. (2006). Language and mind. (3 ${ }^{\text {rd }}$ ed.). New York: Cambridge University Press.

Danziger, S., \& Ward, R. (2010). Language Changes Implicit Associations Between Ethnic Groups and Evaluation in Bilinguals. Psychological Science, 21(6), 799-800.

Forster, M.N. (2012). Kant's philosophy of language? Tijdschrift voor filosofie. 74, $485-511$.

Geertz, C. (1973). The Interpretation of Cultures: Selected Essays. New York: Basic Books.

Goldstein, E.B. (2008). Cognitive Psychology: Connecting mind, research, and everyday experience, (2nd ed.) Thomson Wadsworth

Kendall, D. (2015). Sociology in our times (11 $1^{\text {th }}$ ed.) Boston, MA: Centage Learning.

Krauss, R. M. (1987). The role of the listener: Addressee influences on message formulation. Journal of Language and Social Psychology, 6, $81-98$. 
Kelechi Chijioke Samuel, Adv. J Social Sci.; Vol. 5 Issue 1, pp: 26-36, 2019

Krauss, R.M., \& Chiu, C. (1998). Language and social behavior. In D. Gilbert, S. Fiske \& G. Lindsey (Eds.), Handbook of social psychology (4th ed.), 2, 41-88. Boston, MA: McGraw-Hill. Retrieved June 3, 2016.

Lakoff, R. (1973). Language and woman's place. Language in Society, 2(1), 45-80.

Lotter, D. (2016). Gottlob Frege: Language. In The Internet Encyclopedia of Philosophy.

Mead, G. (1964). Selected writings (A. Reck, Ed.). Chicago: University of Chicago Press.

Ogunnaike, O., Dunham, Y., \& Banaji, M. R. (2010). The language of implicit preferences. Journal of Experimental Social Psychology, 46(6), 999-1003.

Pinker, S., \& Bloom, P. (1990). Natural language and natural selection. Behavioral and Brain Sciences, 13, 707-784.

Rabushka, A., \& Shepsle, K.A (1972). Politics in plural societies: A theory of democratic instability. In J.C Walke (Ed.) Merrill political science series. Charles E. Merrill: Columbus, Ohio

Reddy, M.J. (1979). The Conduit metaphor - A case of frame conflict in our language about language. In A. Ortony (Ed.), Metaphor and thought, 284-324. Cambridge: Cambridge University Press.

Sapir, E. (1921). Language: An Introduction to the Study of Speech. Harcourt, Brace

Schober, M. F. (1993). Spatial perspective-taking in conversation. Cognition, 47, 1-24.

Searle, J. R. (1969). Speech acts: An essay in the philosophy of language. Cambridge: Cambridge University Press.

Smith, K. (2016). Descartes' theory of ideas. In E.N. Zalta (Ed.), The Stanford Encyclopedia of Philosophy. (Winter 2016 ed.).

Spender, D. (1980). Man made language. ( $2^{\text {nd }}$ ed.). London: Pandora press.

Tannen, D. (1993). Gender and Conversational Interaction. (Ed.). New York: Oxford University Press.

Weiten, W. (2007). Psychology: Themes and variations. (7th ed.). United States: Thomson Wadsworth.

Publish your research article in AIJR journals-

$\checkmark$ Online Submission and Tracking

$\checkmark$ Peer-Reviewed

$\checkmark$ Rapid decision

$\checkmark \quad$ Immediate Publication after acceptance

$\checkmark$ Articles freely available online

$\checkmark$ Retain full copyright of your article.

Submit your article at journals.aijr.in
Publish your books with AIJR publisher-

$\checkmark$ Publish with ISBN and DOI.

$\checkmark$ Publish Thesis/Dissertation as Monograph.

$\checkmark$ Publish Book Monograph.

$\checkmark$ Publish Edited Volume/ Book.

$\checkmark$ Publish Conference Proceedings

$\checkmark \quad$ Retain full copyright of your books.

Submit your manuscript at books.aijr.org 